\title{
Integrating forests and biodiversity in Nepal's National Adaptation Plan: A review and synthesis of knowledge stock on opportunities and way forward
}

\begin{abstract}
G. Karki ${ }^{1 *}$, B. Paudel ${ }^{2}$ and B. K. Uprety ${ }^{2}$
Climate change brings lasting changes in forests and biodiversity together with the ecosystem services altering its ability to support present and future economic activities. Current forest utilization and preservation is based on how forests developed under past climatic conditions. Policy-makers and forest managers must accept that climate change is inevitable and from which forests and forest communities are significantly impacted globally and in Nepal also, sustainable forest management (SFM) is already based on many measures to adapt to climate change as planned adaptation will reduce vulnerability at intervened sites and will have long term impacts. However, many forest species will be adapting autonomously and society will have to adjust to the result. Adaptation requires planning for change so that a suite of options for the future but based on the present practice and knowledge is to be available whenever needed. On the foundation of concurrent learning, knowledge and experiences of National Adaption Program of Action (NAPA) process, the National Adaptation Plan (NAP) process for forests and biodiversity will build medium and long-term adaptation strategies and plans with widely accepted objectives of future forests and biodiversity management.
\end{abstract}

Key words: Adaptation, biodiversity, climate change, forest, NAP

O limate change is one of the pronounced global challenges for our civilisation which is calling for immediate responses to tackle its impacts for the sake of current as well as future generations. The changing climate has been affecting all economic sectors and complicatedly intertwined with multiple environmental pressures such as loss of biodiversity, deforestation, forest and land degradation, desertification, water and air pollution, etc. Including other sectors, forests and biodiversity in Nepal is highly vulnerable to climate change due to climate variability and associated risks of the natural disasters (MoE/NAPA, 2010). The effective response to climate change requires urgent formulation and implementation of comprehensive strategic plans and programmes that could halt the damages posed by climate change and prepare the economic sectors and population to adapt with. Nepal commenced systematic adaptation planning based on the vulnerabilities after the National Adaptation
Programme of Action (NAPA) process in 2010. Understanding that NAPA is intended to reduce climate change vulnerabilities through urgent and immediate actions, the National Adaptation Plan (NAP) process has been put forward to address medium and long-term climate change adaptation needs.

Nepal, a least developed Himalayan country, characterized by high levels of poverty, dense population, exposure to climate-related events, and their reliance on flood and drought-prone agricultural land (NCVST, 2009; IDS et al., 2014), is one of the most vulnerable countries to the impacts of climate change. The ongoing climatic change and changes projected to occur are likely to have impacts on forests and biodiversity which urge for comprehensive adaptation actions.

Climate change adaptation considerations in forest and biodiversity management plans

1 Thematic Lead-Forests and Biodiversity in NAP Process * E-mail: gyanendra.karki@forestrynepal.org

2 NAP Formulation Process/Ministry of Population and Environment 
articulating specific goals and objectives for climate change will help to create better avenues for adaptation in forestry sector. A clear statement of goals and objectives based on current trend and future scenario of climate change can lead to an achievement of stated goal that addresses long- term concerns within short-term decisions (Gregory et al., 2001).

This paper collates information on major climate change impacts on forests and biodiversity and the response to address impacts of climate change through policy and programmes. It envisions to review the policy measures and the programmes undertaken to address impacts of climate change in the sector. As Nepal is formulating NAP, which is aimed at reducing vulnerability and integrating adaptation into the development planning process (LEG, 2012), it is imperative to assess the key gaps and needs in the forestry sector which accounts for $15 \%$ of GDP of the country (MoPE, 2017 ) with a potential to generate employment for about 100,000 man- days per year (MSFP, 2015). Moreover, forests in Nepal have a total carbon stock of 1,054.97 million tonnes (DFRS, 2015), the trading of which could further offer additional economic contributions for adaptation actions. Hence the idea of this paper emphasizes on creating an enabling policy environment for the NAP formulation process by understanding the existing situation and future requirements.

\section{Materials and methods}

This study is a synthesis of the knowledge stock and is based on the review of published reports, journal articles and research papers. Information was drawn from national repositories. The policy provisions were reviewed from Nepal's policies, strategies, plans, and gaps and needs were identified accordingly. In addition, national experiences, consultations with key experts and their judgment also flourished the discussions.

\section{Results and discussion}

Global warming and climate change are the biggest concerns since they affect the whole ecosystem and human population. Its impact on forests and biodiversity is more pronounced and easily understood as this sector is more dependent on climate sensitive natural nurture. In Nepal, early symptoms of climate change due to alarmingly increased temperature have been observed. Forests and biodiversity was considered one of the most climate sensitive and highly affected thematic areas in NAPA (MoE/NAPA, 2010) and the same proposition was adopted in NAP formulation process too where forests and biodiversity is a distinct thematic area.

Climate change poses a new dimension to forest and biodiversity management and planning because forests are not only affected by climate change but also by the climate change affected community and political economy as the mountain forest is expected to be most affected by a changing climate (Gitay et al., 2001, Houghton et al., 2001, IPCC, 2007). In Nepal, forests cover about $45 \%$ of the area (DFRS, 2015), and play a critical role in regulating global and local climate, global carbon and water cycles, and in national economy (Bhatti et al.,2003, Karki, 2013). On contrary, forests are also highly affected by changing climate, with their distribution and characters being largely determined directly or indirectly by climate (Kuusela. 1990, McGuire and Chapin, 2006). By 2100 , global climate is expected to warm by 1.4 to $5.8^{\circ} \mathrm{C}$, but the temperature increase in Nepal is projected to be double than this (IPCC, 2001 and 2007), with major implications for mountain biodiversity and forests. A study by Organisation for Economic Cooperation and Development (OECD) using Global Circulation Model (GCM) at Special Report on Emissions Scenarios (SRES) B2 scenario shows increment of mean annual temperature by an average of $1.3^{\circ} \mathrm{C}, 1.7^{\circ} \mathrm{C}$ and $3^{\circ} \mathrm{C}$ by 2030,2050 and 2100 respectively, in comparison to the 2000 baseline (MoE/NAPA, 2010). In this situation, the NAP process and its outcomes could be a point of departure for further adaptation medium and long-term planning in forests and biodiversity thematic area.

\section{Climate change concerns of forestry sector}

Forest's contributions to the well-being of humankind is enormous and wide-ranging including its input in fostering agriculture and assisting in combating rural poverty and providing decent livelihoods, as about $76 \%$ of Nepal's population depends on forests for their livelihoods (Amatya, 2013), where some 64\% still using fuelwood as a major source of domestic energy (CBS, 2014). In addition to addressing climate change impacts, forests also offer green growth 
opportunities and provide vital environmental services such as conserving biodiversity and watersheds. With providing essential goods and services, sustainably managed forests ultimately contribute to sustainable development. Therefore, forests and their roles have also been strongly recognized in the sustainable development goals (NPC, 2015). Forests are not only the livelihoods base of rural community, but they are also one of the key economic sectors of Nepal (Subedi et al., 2014), it contributes to the national economy by providing an average annual revenue of NPR 550 million (USD 5.4 million). Moreover, the sale of different forest products and services, including timber, non-timber forest products (NTFPs) and nature-based tourism, has become a significant source of national revenue (Subedi et al., 2014).

Nepal houses 118 ecosystems, 75 vegetation types and 35 forest types (BPP, 1995; Jackson, 1994; MoFSC, 2014) and is characterized by a high number of floral and faunal diversity (Table 1). Majority of the ecosystem are reported to be found in the Mid Mountain (52 ecosystems) and in the High Mountain (38 ecosystems) (MoFSC, 2014). Out of these ecosystems, 80 ecosystems are in the existing protected areas that cover $23.23 \%$ of the country's area (DNPWC, 2016). $\mathrm{Xu}$ et al. (2009) have projected that a $1^{\circ} \mathrm{C}$ increase in mean annual temperature will result in a shift in isotherms about $160 \mathrm{~m}$ in elevation or $150 \mathrm{~km}$ northward in mountain ecosystems. Nepal is experiencing intense rainfall and/or drought with increased frequencies of landslides, floods, droughts, and forest fires and with accelerated damage to life and property but no clear and significant trend has been noticed in rainfall pattern (MoE/NAPA, 2010). There is an increase at an average annual precipitation of $3.6 \mathrm{~mm}$ from 1976 to 2005. However, observed precipitation has reached over $40 \mathrm{~mm} /$ year in some small pocket areas while decreased annual rainfall has been observed in most parts of midwestern development region (Baidya et al., 2007 and JVS/GWP, 2015). These statements indicate that a small change in the temperature will have dramatic change in the precipitation which is the major attribute of sustainable forest and biodiversity management.
Table 1: Floral and faunal diversity in Nepal

\begin{tabular}{|l|l|l|l|}
\hline \multicolumn{2}{|l|}{ Floral diversity } & \multicolumn{2}{l|}{ Faunal diversity } \\
\hline Group \# of species & \multicolumn{2}{l|}{ Group \# of species } \\
\hline Angiosperm & 6973 & Mammals & 208 \\
\hline Gymnosperm & 26 & Birds & 867 \\
\hline Bryophyte & 1150 & Reptiles & 123 \\
\hline Pteridophyte & 534 & Amphibians & 117 \\
\hline Fungi & 1822 & Fish & 230 \\
\hline Lichens & 465 & Butterflies & 651 \\
\hline Algae & 1001 & Moths & 3958 \\
\hline & & Spider & 175 \\
\hline & & Others & 5642 \\
\hline Total 11971 & & $\mathbf{1 1 8 6 1}$ & \\
\hline
\end{tabular}

Source: MoE, 2010; MoFSC, 2014

Another climate change concern of forestry sector is vulnerability to forest fires in Nepal. Forest fires occur annually in all physiographic/ climatic regions of Nepal. Rimal et al. (2015) analysed The International Centre for Integrated Mountain Development- Moderate Resolution Imaging Spectroradiometer (ICIMOD-MODIS) based forest fire detection and monitoring system data until 2013 and found that Terai region is the most vulnerable to forest fires. Forest fire is a serious driver of forest degradation with increased incidents in Nepal and is one of the toughest threats to forest conservation in Nepal (Karki et al., 2013 and Karki, 2015a, 2015b) which has two fold implication i.e. it's a source of Greenhouse Gas (GHG) emission and the accelerated climate change due to GHG emission triggers more forest fires. Both preparedness and combating forest fires is further compounded in the hills and mountains due to remoteness, and this is accelerated by prolonged droughts in recent years. Furthermore, introduction of alien invasive species is another concern but very few data available on the magnitude and impacts and infestation of alien invasion. Invasive species invade degraded forests and then colonize the site gradually. The central and eastern parts of Nepal seem to have high infestation by invasive species in comparison to the western parts (Rai et al., 2012) 
Like for other biological systems, both temperature and precipitation are critical to forests. In general, warmer and wetter will enhance forest growth, while warmer and drier will likely be detrimental. If drying is significant, grasses will often replace forests in natural systems (Bowes and Sedjo, 1993) where for the $2 \mathrm{xCO} 2$ climate, a poleward shift of vegetation by $500 \mathrm{~km}$ or more is assumed (Solomon and Kirilenko, 1997). In general, climate change is likely to shift natural forests toward the poles (to high altitude also). Thus, for forests, the changes will be the greatest in the temperate climate. For forests growth and composition, perhaps changes in precipitation and moisture is more important than change in temperature because limits on moisture could result in forestlands being converted to grasses. Although climate models are not generally regarded as good predictors of regional precipitation changes, the interiors of continents tend to be dry, and this tendency should be exacerbated under climate change and warming (Sedjo, 2010).

Some impacts of climate change on forests are likely to be beneficial also. Increased temperature could have direct effects on plant growth by enhancing photosynthesis and respiration rates, and plants can tolerate even extremely high temperatures, if sufficient water is available (Kirschbaum, 1998). Sensitivity of natural systems like forests is linked to the projected climate change-induced impacts, the degree to which natural systems have been degraded and the unsustainable utilization of resources. Among forest species, NTFPs are directly exposed and more sensitive to climate change. Declined productivity of economically viable NTFPs, such as panch aunle (Dactylorhiza hatageria), silajit (Rock exudates), amala (Phyllanthus emblica), ritha (Sapindus mukurosii), timur (Zanthoxylum armatum), and bel (Aegle marmelos) have been observed as a result of climate change (MoFSC, 2011). A decrease in the availability of NTFPs will impact the communities dependent on these resources for their livelihoods (MoPE, 2017). Increase in population often result in the conversion of forest lands to cultivation and more intensive farming that result to accelerated forest fires and land degradation. There are also expected impacts on soil erosion, fertility in the soils, and depletion of water resources and genetic variability of crops (Sinha et al., 1998; IPCC, 2001).

\section{Impacts of climate change on biodiversity}

Our understanding of the impacts of climate change on Nepal's biodiversity is inadequate (MoPE, 2017). The Millennium Ecosystem Assessment showed that over the past 50 years human activities have changed ecosystems more rapidly and extensively than at any comparable period in our history (MA, 2005). These changes have bagged many net development gains but at growing environmental costs: biodiversity loss, land degradation, and reduced access to adequate water and natural resources for many of the world's poorest people. Biodiversity loss matters because species and habitats are the building blocks on which human livelihoods depend, the foundation for production forests, fisheries and agricultural crops. Enhanced protection and management of biological resources will also contribute to solutions as nations and communities strive to adapt to climate change (World Bank, 2008). The risk of climate change to human systems is increased by the loss of ecosystem services that are supported by biodiversity (e.g., water purification, protection from extreme weather events, preservation of soils, recycling of nutrients, and pollination of crops). Studies since the Fourth Assessment Report (AR4) broadly confirm that a large proportion of species are at increased risk of extinction (Oppenheimer et al., 2014).

Nepal houses about 12000 faunal species (MoFSC, 2014). A smaller change in temperature significantly affects the rich biodiversity of Nepal making it more vulnerable. Natural disasters, such as landslides, glacial lake outburst floods and drought which have been triggered by climate change pose considerable threat to ecosystems and the people (MoFSC, 2014). Further, global warming may cause forest damage through migration of forests towards the polar region, change in their composition, and extinction of species. Tropical forest and warm temperate forest would disappear, and cool temperate vegetation would turn to warm temperate vegetation. Vegetation pattern would be different under the incremental scenario (at $2^{\circ} \mathrm{C}$ rise of temperature and $20 \%$ rise of rainfall) than the existing types (Sedjo, 2010; Bazzaz, 1998). In this situation, species with narrow tolerances may vanish by virtue of the extinction of their habitat. 
Detail impacts of climate change on Nepal's biodiversity are inadequate as less research have been conducted in this sector. Some of the known impacts are: (i) shifts in agro-ecological zones, prolonged dry spells, and higher incidences of pests and diseases, (ii) increased temperature and rainfall variability, (iii) increased emergence and quickened spread of invasive alien plant species, (iv) increased incidence of forest fire in recent years, (v) changes in phenological cycles of tree species, (vi) shifting of tree line in the Himalaya, and (vii) depletion of wetlands (MoE/NAPA, 2010). The following are some of the likely impacts of climate change on biodiversity:

a. The climatic range of many species will move upward in elevation from their current locations. Having differential effects, some species will migrate through fragmented landscapes whilst others may not be able to do so. Many species that are already vulnerable are likely to become extinct. Species with limited climatic ranges and/ or with limited geographical opportunities (e.g., mountain top species), species with restricted habitat requirements, and/or small populations are typically the most vulnerable (Xu et al., 2009).

b. Changes in the frequency, intensity, extent, and locations of climatically and nonclimatically induced disturbances will affect how and at what rate the existing ecosystems will be replaced by new plant and animal assemblages. The High Himal and High Mountain ecosystems are likely to be worst affected by climate change. Among the natural habitats, remnant native grasslands are highly vulnerable to the impacts of climate change (BCN and DNPWC, 2011). The impacts of climate change are likely to increase in future, which will not only affect biodiversity but also livelihoods of millions of local and indigenous people who depend on biodiversity. Disruption of ecological services on which they depend due to climate change is expected to especially affect the poorest and most vulnerable communities (UNEP, 2010).
National adaptation plan formulation process and forestry sector

Nepal's NAP is aimed at building on the experiences of the MoE/NAPA (2010) and Local Adaptation Plan for Action (LAPA) implementation. NAPA provides a process for the Least Developed Countries (LDCs) to identify priority activities that respond to their urgent and immediate needs to adapt to climate change - those for which further delay would increase vulnerability and/or costs at a later stage (UNFCCC, 2016). Since vulnerability to climate change, particularly in the LDCs, is increasing over the years, 16th Conference of the Parties (COP) to the UNFCCC in 2010, realized the need for the medium and long-term adaptation together with addressing the most urgent and immediate adaptation needs. Under the Cancun Adaptation Framework (CAF), the COP16 established a process to enable LDC Parties to formulate and implement NAP, and established Adaptation Committee to promote implementation of enhanced action on adaptation.

The NAP aims to reduce vulnerability to the impacts of climate change by building adaptive capacity and resilience. The objective is to facilitate integration of climate change adaptation, in a coherent manner, into relevant new and existing policies, programme and activities, in particular development planning processes and strategies, within all relevant sectors and at different levels, as appropriate. Having climate change adaptation (CCA) a high priority at national development discourse, Nepal has been amplifying its efforts on raising awareness and building capacities in climate change along with creating enabling policy environment in addressing climate change in Nepal.

In the context where impacts of climate change are likely to couple up in the decade or so, forestry sector's challenge is to conserve pristine biodiversity values together with fulfilling the need of growing population and infrastructure development. Taking into account of the experience and outcomes of the NAPA process, the Thematic Working Group (TWG) on Forests and Biodiversity has been led by the MoFSC. As the lead, MoFSC is expected to coordinate with all stakeholders, facilitate the process of vulnerability and risk assessment (VRA), propose 
medium and long-term adaptation options, inter alia, develop effective financial mechanism and institutional framework in line with the new governance system.

\section{Key gaps and challenges}

Nepal has formulated many plans and policies in Forests and Biodiversity sector. However, there are critical gaps that need to be addressed to effectively address the increasing threats of climate change. Impacts of climate change cannot be and must not be denied while addressing other conservation and forests management and economic development issues in policy discourse. Broadly, the gaps include, a) Inadequacy of policy to identify the poor and for providing special facilities on the basis of the identity, b) effectively addressing the emerging global challenges including climate change, c) the mechanism of benefit sharing between the state, developer and local communities on the use of local natural resources and d) the occasional conflicts between policies and acts that tend to take a long time to resolve.

The institutional gap, at first, points to the organizational structure of MoFSC. Except creating REDD Implementation Centre (which is basically not for adaptation), There is neither in the ministry nor in the departments, a designated desk to deal with climate change adaptation exist. Both Forest Policy 2015 (MoFSC, 2015) and Forestry Sector Strategy 2014(MoFSC, 2014b) have clearly articulated the action points on climate change adaptation and mitigation including institutional reform, which urges forestry sector to lead the local adaptation planning and implementation process through existing forest user groups. But, a true translation of those strategic points into action is yet to be observed. Other issues are the focus on a top-down approach in implementation, lack of effective monitoring mechanisms, and weak inter-sectoral and interagency coordination. The projects implemented in forestry sector have multiple significance on climate change but institutional synthesis, memory and collection and replication of good practice are still missing. These gaps have delayed decision making, leading to poor implementation, lack of an enabling environment, poor compliance and social safeguards, inadequate devolution to local bodies as envisaged by decentralization policy, and inadequate resources (human and financial) and technology for effectively designing and implementing the adaptation actions.

Data gap and limitation is another challenge. While preparing the vulnerability assessment report for the MoE/NAPA (2010), use of expert judgement particularly in assigning weights to the various climate indicators was necessarily subjective. This has somehow missed the real vulnerability and hence further work is required on the sensitivity, risk/exposure, and adaptation capability indices and consequently the outputs on the basis of these indices, which hopefully need to be considered and the problems should be rectified in the NAP process. Moreover, there is limited research on assessing vulnerability, exposure and climate change impact on forests and biodiversity since it demands long-term engagement (MoFSC, 2010).

Setting the goal of future forests and biodiversity is next pertinent challenge. The policy and strategic documents have stated broader forest management goals that anticipate a desired outcome, and objectives describe the range of conditions that are necessary to achieve management goals. Within the context of climate change, the determination of the potential range of future conditions that could occur under different climate scenarios is expected together with its relation to the desired future conditions. Second, while the influence of climate change on forest ecosystems poses new questions as to how sustainable forest and biodiversity management can be achieved (Spittlehouse and Stewart, 2003), in Nepal also, the existing principles and practice of SFM within all forest management regimes embody many of the activities that will be required to respond to the effects of climate change on forests.

Nepal is comparatively new in systematic forest management although significant achievements are in place within a course of half century practice. Nepal has rejuvenated the denuded forest lands and equally conserved the globally endangered and rare ecosystems including flora and fauna. However, at the interface of climate change, there are several challenges including (i) enhancing knowledge of the impact of climate change on ecosystems and species, (ii) mitigating the negative impacts of climate change, (iii) 
promoting ecosystem-based adaptation methods and (iv) keeping people's involvement intact in managing forest and conserving biodiversity Additional issues include how to strengthen the process for translating the policy into implementation; mitigation of dependence on foreign technology for climate change adaptation due to inability to develop domestic technology; strategic enhancement; evaluation of the contributions of local genetic resources in climate change adaptation; and need to strengthen monitoring mechanism and system (NPC, 2015).

\section{Opportunities in the NAP process for Forests and Biodiversity sector}

NAP process is an opportunity to integrate adaptation into the forests and biodiversity policies, strategies, plans and programme. As NAP is expected to develop adaptation measures for medium and long-term, it is imperative to consider the major objective of the forests and biodiversity such as conservation of biological diversity, maintenance of productive capacity, forest health and vitality and contribution to global carbon cycles. Further it is important to rationalize on how to adapt forestry policies and actions to achieve these objectives in changing climate to meet the needs of societies and adoption of present legal, institutional, and economic framework for forest conservation and sustainable management. As for the NAP process, vulnerability and risk assessment framework put forth by AR5 of IPCC has been considered, the gaps that was encountered during the NAPA vulnerability assessment could be addressed where holistic science (data based) approach could be used in assessing the vulnerability. It is also an opportunity to refine and validate the data that are available in forestry and biodiversity sector.

Although generic adaptation options for forestry are available in the literature (e. g., Spittlehouse and Stewart, 2003; Ogden and Innes, 2008), little research outcomes are available to evaluate their applicability in a local or applied context of forestry. In relation to climate change adaptation, structured decision making is required that involves: (1) establishing management objectives for the future forest, which are considered to be synonymous with the internationally agreed upon criteria for SFM; (2) determining the vulnerability of forest ecosystems, forest communities, local economies, and human populations; (3) developing alternative adaptation options; (4) evaluating alternative options against management objectives; (5) implementing desired adaptation policies and measures; (6) monitoring the effectiveness of climate change adaptation efforts in achieving management objectives; and (7) modifying management practices when adaptation efforts are not successful in meeting management objectives (e.g., adaptive management) (Ohlson et al. 2005; Ogden and Innes, 2008).

Current forest utilization and preservation is based on how forests developed under past climatic conditions. Policy makers and forest managers must accept that climate change is probable and that forests and forest communities face significant impacts. Adaptation requires planning for change so that a suite of options for the future but based on the present practice and knowledge is to be available whenever needed. For a smooth facilitation of this process, a number of questions of forest management must be addressed (Spitlehouse et al., 2003), such as, current research needs to aid development of strategies for climate change adaptation; capacity needs of the forestry community to enhance awareness and to facilitate adaptation at all levels; forest management actions implemented now that reduce compromise in future responses; policy and strategies need to be in place to facilitate adaptation in forests and biodiversity; current knowledge base and monitoring systems adequate to spot problems tempted by climate change soon enough to allow implementation of an acceptable response, which forest ecosystems and species will have to adapt autonomously and where we can intervene a planned adaptation, etc.

Nepal is now to formulate a clear vision that can lead the country to undergo rapid socioeconomic transformation to become a prosperous middleincome country (NPC, 2015). In this connection the NAP process is going to be instrumental to envision the climate change risks to sustainable development and propose and implement adaptation measures to halt the damages posed by climate change. On top, the new local governance system has transferred more responsibilities to the local level, where if the NAP process could give a clearer current picture with future scenario, could 
facilitate the local authorities to better plan for adaptation for not only forests and biodiversity but for all resource and service sectors.

\section{Conclusions and recommendations}

The impacts of climate change on forests and biodiversity are very complex compared to other sectors. Climate change induced risks projected in the Greater Himalayas, however, cannot only be addressed by a natural process of gradual adaptation. Consolidated and coordinated adaptation interventions have to be in place considering the local knowledge, tools and practices. Climate change, no action to tackle it, is the greatest threat to growth. The longer we wait, the harder and more expensive it will be and the costs will be the greatest for the developing world (Freer-Smith et al., 2007). In this backdrop, as forests and biodiversity sector is more exposed to climate change, it is one of the highly sensitive and thus highly vulnerable sector.

Forests are not only impacted by the climate change itself, they are also facing surmounted pressure from the people and communities affected by climate change as well. Forests and climate change are fundamentally linked, in ways that range beyond carbon. The uncertainties associated with projections of climate change and associated impacts emphasize the need to identify robust but flexible management strategies that are likely to achieve the SFM goals and are likely to implement well across a wide range of potential future climate conditions (Ogden and Innes, 2008). Flexible and responsive strategies to new information is sought (Lempert et al., 2003), specifically to incorporate the principles of adaptive management as climate change scenarios are associated with irreducible uncertainties originating from a variety of factors, including a lack of information, long time scales, complexity of the climate system, measurement error and disagreement about structural models (Moss and Schneider, 2000; Kalindikar et al.. 2005). Climate change brings lasting changes in the ecosystem services altering its ability to support present and future economic activities which have already been observed in the mountains of Nepal. Unlike environmental problems, which are local and can be solved by relatively short-term interventions, climate change requires lasting solutions with coordinated and harmonised interventions in the long term.

For Nepal, which is more vulnerable and has fragile geography and socio-economy, climate change adaptation strategy should be viewed as part of the risk management component of a sustainable forest and biodiversity management plan under future climate change where adaptation should be facilitated by successful traditional technologies and practices used over the centuries. It should also be coupled by incorporation of climate change concerns into resource use and development decisions and plans for regularly scheduled investments. The NAP process, need to recognise the key area of interventions for future adaptation planning within the national strategic thrust. With these all considerations in the light of the NAP Guidelines, Nepal has developed a 'NAP Approach' and framework for VRA. An inclusive and wider representative thematic working group (TWG) is in place. The immediate next step is to capacitate the TWG and involve in this iterative process to produce a functional NAP document that could address the anticipated climate risk and vulnerability of thematic area including all sectors and support in climate resilient development pathway.

\section{Acknowledgements}

The NAP Process in Nepal has been led by the Ministry of Population and Environment and supported by the UKAid, ACT, OPM and Practical Action.

\section{References}

Amatya, S. M. 2013. Financing for Sustainable Forests Management in Nepal. INDUFOR, Auckland, New Zealand. Available on: http://www.un.org/esa/forests/

Baidya, S. K., Regmi, R. K. and Shrestha, M. L. 2007. Climate Profile and Observed Climate Change and Climate Variability in Nepal. Department of Hydrology and Meteorology, Kathmandu Nepal.

Bazzaz, F. A. 1998. Tropical forests in a future climate: changes in biological diversity and impact on the global carbon cycle. In Climate Change, Special Issue: Potential Impacts of Climate Change on Tropical Forest Ecosystems (ed.) Schneider, S. H., 
Kluwer Academic Publishers, London, $177-336$.

BCN and DNPWC. 2011. The State of Nepal's Birds 2010. Bird Conservation Nepal (BCN) and Department of National Parks and Wildlife Conservation (DNPWC), Kathmandu, Nepal.

Bhatti, J. S., Van Kooten, G. C., Apps, M. J., Laird, L.D., Campbell, I. D., Campbell, C., Turetsky, M. R.,Yu, Z. and Banfield, E. 2003. Carbon balance and climate change in boreal forests. In Towards Sustainable Management of the Boreal Forest (eds.) Burton, P.J., Messier, C., Smith, D.W. and Adamowicz, W.L., National Research Council of Canada, Ottawa, Ontario, Canada, 799-855.

Bowes, M. and Sedjo, R. 1993. Impacts and responses to climate change in forests of the MINK Region. Climatic Change 24: $63-82$.

BPP. 1995. Biodiversity Project Profile. Government of Nepal/Netherlands.

CBS. 2014. Environment Statistics of Nepal. Central Bureau of Statistics, Kathmandu, Nepal. DFRS. 2015. State of Nepal's Forests. Forest Resource Assessment (FRA) Nepal, Department of Forest Research and Survey (DFRS). Kathmandu, Nepal. ISBN: 978-9937-8896-3-6

DNPWC. 2016. Annual Report (FY 2071/72). Department of National Parks and Wildlife Conservation (DNPWC). Babarmahal, Kathmandu, Nepal.

Freer-Smith, P.H., Broadmeadow, M.S.J., and Lynch J. M (eds). 2007. Forestry and Climate Change. CAB International, 2007.Wallingford U.K.;

Gitay, H., Brown, S.,Easterling, W. and Jallow, B. 2001. Ecosystems and their goods and services. In Climate Change 2001: Impacts, Adaptation, and Vulnerability, (eds.) Pages 235-342 in McCarthy, J. J., Canziani, O. F., Leary, N. A., Dokken, D. J. and White, K. S., Contribution of Working Group II to the TAR of the Intergovernmental Panel on Climate Change. Cambridge University Press, Cambridge and New York, 235-342.
Gregory, R., McDaniels, T. L. and Fields, D. 2001. Decision-aiding not dispute resolution: creating insights through structured environmental decisions. Journal of Policy Analysis and Management 20 (3): 415432.

Houghton, J. T., Ding, Y., Griggs, D. J., Noguer, M., van der Linden, P. J., Dai, X., Maskell, K. and Johnson,C. A. (editors). 2001. Climate Change 2001: the Scientific Basis. Contribution of Working Group I to the Third Assessment Report of the Intergovernmental Panel on Climate Change. Cambridge University Press, Cambridge and New York.

Jackson, J. K. 1994. Manual of Afforestation in Nepal. 2nd edition. Forest. Research and Survey Centre, Kathmandu, Nepal.

JVS/GWP. 2015. Stocktaking: Climate Vulnerability on Agricultural Sector for National Adaptation Plan Process. Jalsrot Vikas Sanstha (JVS)/GWP Nepal March 2015.

IDS-Nepal, PAC and GCAP. 2014. Economic Impact Assessment of Climate Change in Key Sectors in Nepal. IDS-Nepal, Kathmandu, Nepal.

IPCC. 2001. Climate change 2001: Impacts, adaptation, and vulnerability. In Contribution of Working Group II to the Third Assessment Report of the Intergovernmental Panel on Climate Change (eds.) McCarthy, J. J., Canziani, O. F., Leary, N. A., Dokken, D. J. and White, K. S., Cambridge University Press, Cambridge, United Kingdom and New York, USA.

IPCC. 2007. Energy Supply. In The Assessment Report of Working Group III. Chapter 4. New York: Cambridge University Press. http://www.ipcc.ch/ipccreports/ar4-wg3. htm

Kandlikar, M. Risbey, J. and Dessai, S. 2005. Representing and communicating deep uncertainty in climate-change assessments. Geosciences 337 (4) : 443-455.

Karki, G. 2015a. Climate Change Vulnerability Assessment and Potential Adaptation 
Measures for Local Communities of the Chure Project Area. WWF Nepal.

Karki, G. 2015b. Forest Fire Hazard Mapping of Chandranigahpur (Rautahat) and Ratanpuri (Bara) VDCs. WWF Nepal, Sustainable Land Management Project, Kathmandu, Nepal.

Karki, G., Acharya, R. P., Dhakal, S. and Sharma, R. 2013. A WWF/Hariyo Ban commissioned Forest Fire Hazard Mapping of Gorkha District, Final Report.

Karki, M. 2013. Green economy for sustainable development in Nepal: Role of Forestry Sector. The Initiation. Vol 5 (2013) : 96109

Kirschbaum, MUF. 1998. The impacts of climate change on the growth and ecology of tropical forests. In Tropical Forests and Climate Change: Status, Issues and Challenges (TFFC'98), Proceedings of the International Conference on, College of Forestry and Natural Resources, University of the Philippines, Los Banos, Philippines,19-44.

Kuusela, K. 1990. The Dynamics of Boreal Coniferous Forests. Finnish National Fund for Research and Development (SITRA), Helsinki, Finland.

Least Developed Countries Expert Group (LEG). 2012. National Adaptation Plans. Technical Guidelines for the National Adaptation Plan Process. Bonn: UNFCCC secretariat. Bonn, Germany. December 2012.

Lempert, R. J., Popper, S.W. and Bankes, S.C. 2003. Shaping the Next One Hundred Years: New Methods for Quantitative, Long-term Policy Analysis. RAND Corporation, Santa Monica, California, USA.

McGuire, A. D. and Chapin, F.S. 2006. Climate feedbacks in the Alaskan boreal forest. In Alaska's Changing Boreal Forest, (eds.) Chapin III, Oswood, M. W., Van Cleve, K., Viereck, L. A. and Verbyla, D. L. F. S., Pages 309-322 in F. S. Chapin, III, M. W.

Oswood, K. Van Cleve, L. A. Viereck, and D. L.
Verbyla, Oxford University Press, New York, USA, 309-322.

Millennium Ecosystem Assessment (MA). 2005. Ecosystems and Human Well-being: Synthesis. Island Press, Washington, DC, USA.

MoE/NAPA.2010. National Adaptation Program of Action (NAPA) to Climate Change. Ministry of Science Technology and Environment, Kathmandu, Nepal.

MoFSC. 2011. Role of Forest on Climate Change Adaptation. Ministry of Forests and Soil Conservation (MoFSC), REDD - Forestry and Climate Change Cell, Kathmandu, Nepal.

MoFSC. 2014a. Nepal Biodiversity Strategy and Action Plan (2014-2020). Ministry of Forests and Soil Conservation, Kathmandu, Nepal.

MoFSC. 2014b. Forestry Sector Strategy (2012-2022). Ministry of Forests and Soil Conservation, Kathmandu, Nepal.

MoFSC, 2015. Forest Policy 2071. Ministry of Forests and Soil Conservation, Kathmandu, Nepal.

MoPE. 2017. Synthesis of Stock Taking Report for National Adaptation Plan (NAP) Formulation Process in Nepal. Ministry of Population and Environment, Kathmandu, Nepal.

Moss, R.H. and Schneider, S.H. 2000. Uncertainties in the IPCC TAR: recommendations to lead authors for more consistent assessment and reporting. In Guidance: Papers on the Cross Cutting Issues of the Third Assessment Report of the IPCC (eds.) Pachauri, R., Taniguchi, T. and Tanaka, K.,World Meteorological Organization, Geneva, Switzerland, 3351.

MSFP. 2015. Creating Jobs and Income through Forestry in Nepal. Multistakeholder Forestry Programme, Kathmandu, Nepal.

NCVST. 2009. Vulnerability Through the Eyes of Vulnerable: Climate Change Induced Uncertainties and Nepal's Development Predicaments, ISET-N and ISET, Boulder, 
Colorado for Nepal Climate Vulnerability Study Team (NCVST) Kathmandu, Nepal.

NPC. 2015. Sustainable Development Goals, 2016-2030, National (Preliminary) Report. Government of Nepal, National Planning Commission, Kathmandu, Nepal

Ogden, A. E. and Innes, J. L. 2008. Climate change adaptation and regional forest planning in southern Yukon, Canada. Mitigation and Adaptation Strategies for Global Change 13 (8) : 833-861.

Ohlson, D. W., McKinnon, G. A. and Hirsch, K. G. 2005. A structured decision-making approach to climate change adaptation in the forest sector. The Forestry Chronicle 81 (1) : 97-103.

Oppenheimer, M., Campos, M., Warren, R., Birkmann, J., Luber, G., O’Neill, B. and Takahashi, K. 2014: Emergent risks and key vulnerabilities. In Climate Change 2014: Impacts, Adaptation, and Vulnerability. Part A: Global and Sectoral Aspects. Contribution of Working Group II to the Fifth Assessment Report of the Intergovernmental Panel on Climate Change (eds.) Field, C. B., V. R. Barros, D. J. Dokken, K. J. Mach, M. D. Mastrandrea, T. E. Bilir, M. Chatterjee, K. L. Ebi, Y. O. Estrada, R. C. Genova, B. Girma, E. S. Kissel, A. N. Levy, S. MacCracken, P. R. Mastrandrea, and L. L. White, Cambridge University Press, Cambridge, United Kingdom and New York, NY, USA, 1039-1099.

Rai, R. K. and Scarborough, H. 2012. Valuing the Damage Caused by Invasive Plant Species in a Low-income Community in Nepal. SANDEE Working Papers, ISSN 1893-1891; WP 74-1. ISBN: 978-9937596-03-9.

Rimal, B., Karki, G., Trines, E. and Goor, W. V. 2015. Analytical Study on Assessing the Value of Forests, the Political Economy of Land Use and the Carbon Emissions from the Drivers of DD: An Assessment of Drivers of Deforestation and Forest Degradation in Nepal. GoN/MoFSC/ REDD Cell. Kathmandu, Nepal.

Sedjo, R. A. 1993. Economic Aspects of Climate,
Forests, and Fire: A North American Perspective. Environment International 17(2/3): $163-168$.

Sedjo, R. A. 2010. Discussion Paper on Adaptation of Forests to Climate Change: Some Estimates. The Resources for the Future. 1616 P St. NW Washington, DC 20036 202-328-5000.

Sinha, S. K., Rai, M. and Singh, G.B., 1998. Decline in Productivity in Punjab and Haryana: A Myth or Reality ? Indian Council of Agricultural Research (ICAR) Publication, New Delhi, India.

Solomon, A. M. and Kirilenko, A. P.1997. Global ecology and biogeography. Letters 6:139148. Spittlehouse, D. L., and Stewart, R. B. 2003. Adaptation to climate change in forest management. British Columbia. Journal of Ecosystems and Management 4(1): 1-11.

Subedi, B. P., Ghimire, P. L., Khanal, S.C., Gyawali, S., Katwal, P., Sthapit, K. R. and Gauli, K. 2014. Potential of Forestry Sector in Economic Growth and Development: Short Concept Notes on Five Themes. Multi Stakeholder Forestry Programme, Kathmandu, Nepal.

UNFCCC. 2016. Climate Action Now: Summary for Policy Makers (SPM). United Nations Climate Change Secretariat Platz der Vereinten Nationen 153113 Bonn, Germany. UNEP. 2010. Integrated Solutions for Biodiversity, Climate Change and Poverty. UNEP Policy Series 1, Ecosystem Management.

World Bank. 2008. Biodiversity, Climate Change and Adaptation, Nature Based Solutions from the World Bank Portfolio. The International Bank for Reconstruction and Development / The World Bank. 1818 H Street, NW Washington, DC 20433 USA September 2008.

Xu, J. C, Grumbine, R. E., Shrestha, A., Erriksson, M., Yang, X., Wang, Y. and Wilkes, A. 2009. The melting Himalayas: Cascading effects of climate change on water, biodiversity, and livelihoods. Conservation Biology 23 (3): $520-530$. 